\title{
Editorial
}

\section{Animal Ethics - A Cultural Frontier}

nimals occupy an important part of our emotional and cultural psyche. From children's toys to
adult's pets, from a food resource to forms of sport, they are present in our daily lives and thoughts. Since the early days of medicine there have been experiments on animals as surrogates for humans whilst science has used animal experimentation in many ways. Biology in Antarctica is part of this.

In an effort to limit gratuitous cruelty and exploitation, there has been increasing government legislation in developed countries to control and license what can and cannot be done with animals. The degree of control has largely been driven by public pressure, beginning as long ago as the 19th century. Despite efforts to achieve global agreement this has always been a national responsibility.

The Cruelty to Animals Act of 1867 in the UK was the first legislation specifically aimed at controlling the use of animals in science and, since then, many other countries have passed legislation along similar lines. The implementation of this legislation has varied greatly, with some countries requiring licensing and independent ethical committees whilst others have been much less rigorous. Some apply the laws to their nationals everywhere whilst most restrict the application to activities on national territory only.

Such a complex situation cries out for some unification. After all, it is hardly logical that an experiment banned by one country, on say seals, can be undertaken on the same species with impunity by nationals from another country. How even more difficult this becomes when scientists from many countries are working side by side on international territory as in the Antarctic.

Knowles Kerry from Australia recognized this over 25 years ago and developed a draft code based on Australian legislation. With a great deal of effort he piloted the SCAR Code of Ethics for Animal Experiments through SCAR and it reached the Treaty in 1994. Since then the rest of the world has moved on, in many cases developing national laws and extending them to their own scientists working in Antarctica. Many science journals have also adopted requirements that scientists must have followed before their work is acceptable.

SCAR has responded by revising the code in line with the expectations of the 21 st century. None of this is revolutionary and it falls far short of the rules imposed on, for example, British, Australian, and American scientists. International databases suggest that all European Union countries are already covered by EU Directive 86/609/EEC on the protection of animals used for scientific purposes, but for some other countries - for example in South America and Asia - there are still only very basic provisions, if there are any at all.

Back in 1993 important questions were raised. Is there a need for a handbook of acceptable techniques to ensure that no researcher is disadvantaged? Since it is a SCAR Code should SCAR attempt to assess its implementation? How is the Antarctic scientific community to deal with those who choose to ignore it? Should compliance with the Code be included in Treaty inspection questions? And where does COMNAP stand on this?

None of these questions have been answered. Surely biologists in all SCAR countries would want to move forward rather than backward, to mitigate pain and suffering rather than mistreat animals? Let us hope that the new version is agreed by consensus in Buenos Aires and the Code is then forwarded to the Treaty for their agreement. Perhaps this time the questions on implementation and compliance can also be discussed so that the effort is not seen as simply a paper exercise of no lasting value?

D.W.H. WaLton 